(c) American Dairy Science Association, 2003.

\title{
Phosphorus Feeding Levels and Critical Control Points on Dairy Farms
}

\author{
Z. Dou, ${ }^{*}$ J. D. Ferguson, ${ }^{*}$ J. Fiorini, ${ }^{*}$ J. D. Toth, ${ }^{\star}$ S. M. Alexander, ${ }^{*}$ \\ L. E. Chase,† C. M. Ryan,†K. F. Knowlton,‡ R. A. Kohn,§ \\ A. B. Peterson,§ J. T. Sims, $\|$ and Z. Wu\# \\ ${ }^{*}$ Center for Animal Health and Productivity, School of Veterinary Medicine, \\ University of Pennsylvania, Kennett Square 19348 \\ †Dept. of Dairy Science, Cornell University, Ithaca, NY 14853 \\ $\ddagger$ Dept. of Dairy Science, Virginia Polytechnic Institute and State University, Blacksburg 24061 \\ §Dept. of Animal and Avian Science, University of Maryland, College Park 20742 \\ |Dept. of Plant and Soil Science, University of Delaware, Newark 19717 \\ \#Dept. of Dairy and Animal Science, Pennsylvania State University, State College 16802
}

\begin{abstract}
A viable and cost-effective approach to managing $P$ on dairy farms is to minimize excess $\mathrm{P}$ in diets, which in turn leads to less excretion of $\mathrm{P}$ in manure without impairing animal performance. A questionnaire survey was conducted, coupled with on-site feed and fecal sample collection and analysis on dairy farms in New York, Pennsylvania, Delaware, Maryland, and Virginia. The purpose was to assess dietary $\mathrm{P}$ levels and to identify critical control points pertaining to $\mathrm{P}$ feeding management. Survey responses, 612 out of 2500 randomly selected farms, revealed a wide range of dietary $\mathrm{P}$ concentrations for lactating cows, from 3.6 to $7.0 \mathrm{~g} / \mathrm{kg}$ of feed DM. The mean was $4.4 \mathrm{~g} / \mathrm{kg}$, which was $34 \%$ above the level recommended by the NRC for $27.9 \mathrm{~kg}$ milk/d, the mean milk yield in the survey. Higher $\mathrm{P}$ concentrations in diets were not associated with higher milk yields ( $\mathrm{n}$ $=98, \mathrm{R}^{2}=0.057$ for the survey farms; $\mathrm{n}=92, \mathrm{R}^{2}=$ 0.043 for farms selected for on-site sampling). However, higher dietary $\mathrm{P}$ led to higher $\mathrm{P}$ excretion in feces $(\mathrm{n}=$ $75, \mathrm{R}^{2}=0.429$ ), with much of the increased fecal $\mathrm{P}$ being water soluble. Phosphorus concentrations in diet samples matched closely with $\mathrm{P}$ concentrations in formulated rations, with $67 \%$ of the feed samples deviating $<10 \%$ from the formulations. On $84 \%$ of the survey farms, ration formulation was provided by professionals rather than producers themselves. Most producers were feeding more $\mathrm{P}$ than cows needed because it was recommended in the rations by these consultants. In conclusion, $\mathrm{P}$ fed to lactating cows averaged $34 \%$ above $\mathrm{NRC}$ recommendations; to reduce excess dietary $\mathrm{P}$, ration formulation is the critical control point.
\end{abstract}

(Key words: dairy farm, phosphorus, diet modification)

Received May 1, 2003.

Accepted June 17, 2003.

Corresponding author: Z. Dou; e-mail: dou@cahp.vet.upenn.edu.

\section{INTRODUCTION}

The role of $\mathrm{P}$ in agricultural runoff in accelerating the eutrophication of surface waters has been well documented. Increasing attention is given to areas where high potential of runoff and erosion is coupled with high-P soils (Lemunyon and Gilbert, 1993). In many cases, such high-P soils can be found in areas with intensive animal farming operations. This is because continual application of manures has greatly accelerated $\mathrm{P}$ buildup in soils on animal farms. In response to impaired water resources, several states, such as Maryland, Virginia, and Delaware in the United States, are now requiring P-based management practices for fields with soils high in $\mathrm{P}$ and susceptible to runoff and erosion (Sims, 2000). For many animal operations, adopting P-based nutrient management plans would mean restrictions on manure applications. Finding suitable land or landowners willing to receive manures may not be easy in these areas since many of the soils are already high in $\mathrm{P}$ content. Transporting manure to a distant field where manure $\mathrm{P}$ may be better utilized is often problematic because of increased hauling cost as well as safety concerns.

$A$ viable and cost-effective approach to reduce $\mathrm{P}$ surplus on dairy farms is to minimize excess $\mathrm{P}$ fed to animals through diet modification (CAST, 2002). By balancing $\mathrm{P}$ supply and intake against cow requriements, excess $\mathrm{P}$ in diets may be reduced without impairing cow performance and in the meantime decreasing $\mathrm{P}$ excretion in manure. This has been demonstrated by a number of studies in recent years. Results from research trials indicated that dietary $\mathrm{P}$ for lactating cows may be reduced by 20 to $50 \%$ from levels commonly fed on farms without sacrificing milk yield (e.g., Valk and Sebek, 1999; Wu and Satter, 2000; Knowlton and Herbein, 2002). Decreases in excess dietary P not only lower the excretion of total $\mathrm{P}$ in manure, but more importan- 
tly, reduce water-soluble P substantially (Dou et al., 2002). Water-soluble $P$ content in manure correlates significantly with P loss in runoff (Sharpley and Moyer, 2000; Kleinman et al., 2002). As expected, P management via diet manipulation also decreases land acreage requried for spreading manure (Powell et al., 2001).

According to Satter (2003), a typical dairy cow fed with a dietary $\mathrm{P}$ concentration of $4.80 \mathrm{~g} / \mathrm{kg}$ of feed DM would generate $24.7 \mathrm{~kg}$ of $\mathrm{P}$ in manure per lactation $(305 \mathrm{~d})$. This would require approximately 0.81 ha of cropland for spreading manure on a P-based application plan, assuming a $\mathrm{P}$ removal of $12.1 \mathrm{~kg} / \mathrm{ha}$ per year for typical crop yields in the Midwest. In constrast, if the cow is fed at $3.50 \mathrm{~g}$ of $\mathrm{P} / \mathrm{kg}$ of feed $\mathrm{DM}$, an adequate level according to NRC and numerous research projects, the amount of manure $\mathrm{P}$ excretion would be reduced to $15.8 \mathrm{~kg}$ per lactation and the land requirement reduced to 0.53 ha for the Midwest crops, a $35 \%$ reduction. The potential of manure $\mathrm{P}$ reduction by eliminating unnecessary $\mathrm{P}$ in diets is obvious when this estimation is aggregated to regional or national levels. For example, in New York and Pennsylvania, ranked 3rd and 4th in dairy production in the United States with a combined lactating cow population of $1,271,000$ (NASS, 2003), manure $\mathrm{P}$ could be decreased by more than 11 million $\mathrm{kg} / \mathrm{yr}$. Nationwide, an annual reduction of over $80 \mathrm{mil}-$ lion $\mathrm{kg}$ of $\mathrm{P}$ in manure may be achieved for the 9 million lactating cows (NASS, 2003).

The projected decrease in manure $\mathrm{P}$ excretion may not be beyond reach because dietary $\mathrm{P}$ concentrations near or above $4.80 \mathrm{~g}$ of $\mathrm{P} / \mathrm{kg}$ of feed DM are fairly common on farms, as revealed by several recent surveys. Shaver and Howard (1995) tracked the feeding programs of 11 high-producing herds in Wisconsin and found an average of $5.70 \mathrm{~g}$ of $\mathrm{P} / \mathrm{kg}$ of ration DM. The authors commented that TMR formulated at $5.00 \mathrm{~g}$ of $\mathrm{P} / \mathrm{kg}$ of DM were common. Sink et al. (2000) reported $4.90 \mathrm{~g}$ of $\mathrm{P} / \mathrm{kg}$ on 33 Virginia dairies surveyed. Satter and $\mathrm{Wu}$ (1999) reported an average of $4.80 \mathrm{~g}$ of $\mathrm{P} / \mathrm{kg}$ through a telephone survey of university extension personnel, nutrition consultants, and feed industry personnel. Sansinena et al. (1999) reported $4.90 \mathrm{~g}$ of $\mathrm{P} / \mathrm{kg}$ from a survey of dairy nutritionists in the mid-South region.

Various reasons why producers feed more $\mathrm{P}$ than is required have been discussed (Shaver and Howard, 1995; CAST, 2002; Wu, 2003). The fundamental concern with lowering dietary $\mathrm{P}$ is possible impairment of animal health and performance and associated economic loss. This concern must be adequately addressed in order to take advantage of diet modification and promote its wide adoption for enhanced environmental stewardship while sustaining animal production. Toward this end, information originated from commercial operations would be valuable for verifying the results derived from research feeding trials. Such field data may be more persuasive and better received by the farming community.

A project has been initiated recently, involving a large number of dairy farms in five states (New York, Pennsylvania, Delaware, Maryland, Virginia) in the Northeast and mid-Atlantic regions. One of the project goals is to determine the dietary $\mathrm{P}$ range adequate for satisfactory cow performance while minimizing manure $\mathrm{P}$ excretion using farm-based data. This article reports findings from the first phase of the project, including a questionnaire survey coupled with on-site feed and fecal sample collection and analysis results. The specific objective of the present work was to evaluate $\mathrm{P}$ feeding levels and to identify the critical control points pertaining to $\mathrm{P}$ management in dairy herds.

\section{MATERIALS AND METHODS}

\section{Questionnaire Survey}

The five states targeted in the project encompass much of the Chesapeake Bay Watershed in the United States (Figure 1). In 2001, the lactating cow population in these states totaled 1.48 million, and milk production approximated 11.8 million t (NASS, 2003). The cow numbers and milk production accounted for 74 and $73 \%$ of those in the 14 states combined in the Northeast and Mid-Atlantic regions, or 15 and $16 \%$ of U.S. totals (NASS, 2003).

Lists of all dairy operations in the individual states were obtained in November 2001. From these lists, a total of 2500 operations were grouped by state and randomly selected as survey recipients (Figure 1). The survey questionnaire, sent out in January 2002, consisted of 18 queries, which were a mix of open- and closedended questions with multiple choices when applicable. Information sought in the questionnaire included: 1) herd demographics such as breeds, herd size, milk yield, etc., 2) management practices regarding herd nutrition and reproduction, and 3) dietary $\mathrm{P}$ levels and related concerns. A draft questionnaire was previewed by local dairymen as well as university personnel who have frequent contact with producers. Feedback was incorporated into the final version.

Survey responses totaled 617 by the end of April 2002, approximately $25 \%$ of the sampling pool (Figure 1). Data included in the current report were based on 612 valid returns. Some participants chose not to respond to every question in the survey; hence the percentage, when reported, was the percentage response to the individual question. Also, some questions allowed multiple answers and thus data may not total $100 \%$. 


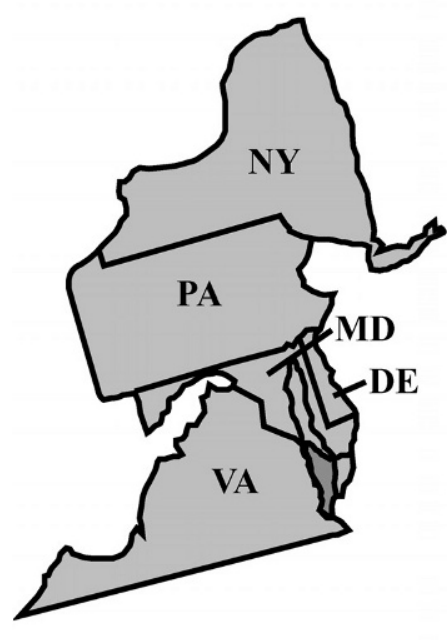

Number of farms included in questionnaire survey and in a follow-up study.

\begin{tabular}{|l|c|c|c|}
\hline State & $\begin{array}{c}\text { Surveys } \\
\text { sent }\end{array}$ & $\begin{array}{c}\text { Surveys } \\
\text { returned }\end{array}$ & $\begin{array}{c}\text { Follow-up } \\
\text { study }\end{array}$ \\
\hline New York & 500 & 100 & 29 \\
\hline $\begin{array}{l}\text { Pennsylvania- } \\
\text { Delaware }\end{array}$ & 1000 & 264 & 41 \\
\hline Maryland & 500 & 138 & 15 \\
\hline Virginia & 500 & 92 & 7 \\
\hline Unknown & & 23 & \\
\hline Total & 2,500 & 617 & 92 \\
\hline
\end{tabular}

${ }^{1}$ State of origin unknown.

Figure 1. A P feeding survey was conducted on dairy farms in five states in the Northeast and Mid-Atlantic regions of the United States. On-site sample collection and subsequent analyses were performed for selected farms in a follow-up study.

\section{On-site Sample Collection}

A total of 92 farms were selected for on-site sample collection during March to August, 2002 (Figure 1), including 35 from the survey response farm pool and 57 solicited from existing extension and education contacts. The selection criteria were based on the requirements of the follow-up study as part of the larger project. As a key element of the selection criteria, the farms must have production record systems in place (e.g., DHIA services) and must utilize professional nutrition and veterinary services. Also, only confined feeding operations were selected. The follow-up (and currently ongoing) study involves evaluation of dietary $\mathrm{P}$ concentration and variability based on seasonal on-farm sampling, and identification of an adequate dietary $P$ range derived from comprehensive analyses of milk production and reproduction records.

On-site sample collection included feed and fecal samples from lactating cows only. Feed samples consisted of TMR for each lactating cow group or individual feed ingredients if the lactating herd was on component feeding. Fecal grab samples were collected from 10 to 20 lactating cows per farm, with the number of samples varying depending on herd size and number of feeding groups. Uniform sampling protocols were used to minimize discrepancies among different sampling personnel from five participating institutions. Feed and fecal samples were collected on the same day on individual farms.
Total mixed ration was collected at the feed bunk at feed delivery, mixed by hand, and randomly subsampled. Grains and silages had 5 to 10 grab samples taken at the silo, bin, or fresh trench face. Fecal samples were taken rectally from healthy lactating cows from each feeding group and stage of lactation. Approximately 0.5-kg bulk samples were taken per cow, hand-mixed, frozen, and forwarded to the University of Pennsylvania for laboratory analysis.

\section{Laboratory Analysis}

Feed samples were analyzed at a commercial laboratory using established procedures for standard feed quality parameters (e.g., CP, soluble proteins, NDF, etc.), including total $\mathrm{P}$ concentrations. Dietary $\mathrm{P}$ concentrations were derived either directly from the feed analyses for TMR samples or, in the case of component feeding, calculated based on the $\mathrm{P}$ concentrations of individual feeds in the laboratory reports and ration formulation information obtained from the farm.

Fecal samples were frozen upon arriving at the laboratories of the participating institutions and kept frozen until analysis. All fecal samples were analyzed at the Environmental Studies Lab at the University of Pennsylvania. Samples were thawed, homogenized by hand, and split into subsamples for determination of: 1) DM in a convection oven at $\left.65^{\circ} \mathrm{C}, 2\right)$ total $\mathrm{P}$ by microwaveassisted acid digestion (Walter et al., 1997) with P con- 
centration analyzed using the phosphomolybdate blue method of Murphy and Riley (1962), and 3) water-soluble $\mathrm{P}$ by extracting $2 \mathrm{~g}$ of wet fecal sample in $98 \mathrm{~mL}$ of deionized water (reciprocal shaker for $1 \mathrm{~h}$, filtered through Whatman 42 paper), with aliquots of the water extract analyzed for inorganic $\mathrm{P}$ by the phosphomolybdate blue method and total P by ICP spectrometry.

\section{Data Analysis}

Analyses of variance and mean separation by Duncan's multiple range test at a significance level of 5\% were performed using the GLM procedure in SAS (SAS Inst., Inc., Cary, NC). A logistic regression model, developed with the SAS logistic program (Allison, 1999), was used to evaluate the association of the dependent dichotomous responses from the survey as a function of herd size (lactating cow number). Concentrations of dietary $\mathrm{P}$ and fecal $\mathrm{P}$ were reported on a $\mathrm{DM}$ basis and as means for the respective farms unless noted otherwise.

\section{RESULTS AND DISCUSSION}

\section{Herd Demographics}

The survey farms had Holstein as the main breed ( $91.3 \%$ of the herds); Jersey accounted for nearly $5 \%$ of the herds and other breeds were reported by a small number of farms. Housing for lactating cows varied from free stalls ( $44.3 \%$ of the herds) to tie stall (26.1\%) and stanchion (14.2\%) plus pasture and mixed housing. About half of the farms reported TMR feeding, but separate feeding of forages and grains was also common (39.8\% of the herds). A total of 19 farms reported intensive grazing. All herds selected for the follow-up study were Holstein but with various housing and feeding systems. Pasture-grazing herds were excluded because the number of farms meeting the requirements of the follow-up study was insufficient to support rigorous statistical testing.

The survey farms had a mean of 84 lactating cows averaging $27.9 \mathrm{~kg} / \mathrm{d}$ of milk per cow. The farms selected for the follow-up study had larger herds with a mean of 281 lactating cows averaging $32.9 \mathrm{~kg} / \mathrm{d}$ of milk per cow. The herd size distribution pattern for farms responding to the survey was similar to that of the fivestate area, but for the selected farms it deviated toward larger herds (Figure 2). Although herd size was not a major consideration during farm selection, larger operations are generally more amenable than smaller ones to participating in research projects or other activities, as indicated by the logistic regression analyses (Table 1). Larger herds also had a higher tendency toward adopting various services, except professionally admin-

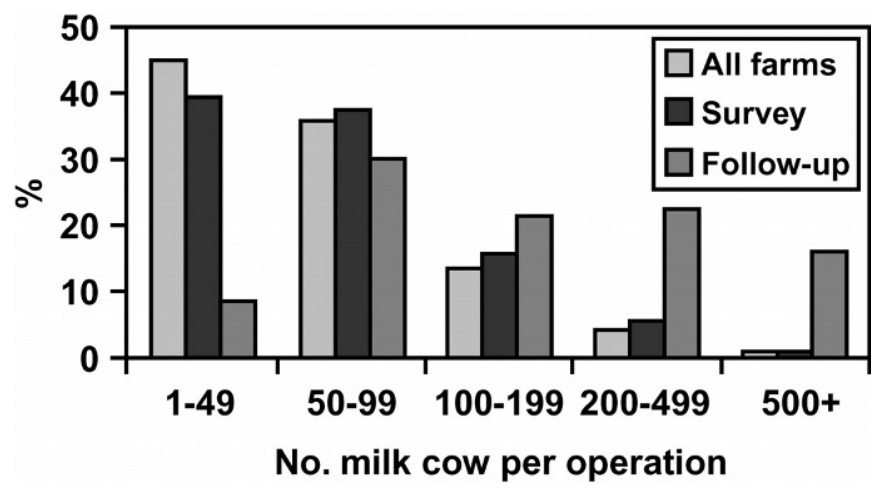

Figure 2. Herd size distribution (\%, lactating cows only) in five states (New York, Pennsylvania, Delaware, Maryland, Virginia) in $2001(n=19,950)$ compared with survey responses $(n=599)$ or farms selected for a follow-up study $(\mathrm{n}=92)$.

istered AI (Table 1); the latter apparently preferred handling by their own employees.

\section{Excess Dietary P Fed on Most Farms}

Survey results indicated a wide range of dietary $\mathrm{P}$ for lactating cows, from 3.6 to $7.0 \mathrm{~g} / \mathrm{kg}$ feed DM (Figure 3 ). The mean was $4.42 \mathrm{~g}$ of P/kg of feed DM. The corresponding NRC (2001) recommendation would be $3.3 \mathrm{~g}$ of P/ of $\mathrm{kg}$ for the mean milk yield $(27.9 \mathrm{~kg} / \mathrm{d}$ per cow). That is, on average, $\mathrm{P}$ was fed $34 \%$ above the NRC guidelines. The results seem to suggest some slight decreases in dietary $\mathrm{P}$ over time, as compared to previous survey findings of $4.8 \mathrm{~g} / \mathrm{kg}$ or greater (Shaver and Howard, 1995; Sansinena et al., 1999; Satter and Wu, 1999; and Sink et al., 2000). Wu (2003) also found decreased dietary $\mathrm{P}$ based on survey responses of 33 producers and 38 nutritionists in Pennsylvania, with dietary $\mathrm{P}$ averaging $3.9 \mathrm{~g} / \mathrm{kg}$ for low-producing groups and $4.4 \mathrm{~g} / \mathrm{kg}$ for high-producing groups.

For the selected farms, dietary $\mathrm{P}$ concentrations based on feed analysis results ranged from 2.93 to 6.45 with a mean of $4.39 \mathrm{~g} / \mathrm{kg}$ of feed DM. On average, these farms fed $\mathrm{P} 26 \%$ above the NRC recommendation for the given milk yield ( $32.6 \mathrm{~kg} / \mathrm{d}$ per cow). That the extent of $\mathrm{P}$ overfeeding on the selected farms (26\%) appeared to be less severe than the survey farms (34\%) may be due to the higher mean milk yield for the selected farms since more $\mathrm{P}$ is recommended for higher milk production (NRC, 2001). There is also a significant relationship between herd size and milk yield. Regression analyses indicated an increase of $0.9 \mathrm{~kg} / \mathrm{d}$ of milk for each 100-cow increase in size for the survey farms $(P=$ 0.0001 ), or an increase of $0.4 \mathrm{~kg}$ of milk/d per 100-cow increase for the selected farms $(P=0.026)$.

To assess the reporting accuracy regarding $\mathrm{P}$ feeding levels, we compared the dietary $\mathrm{P}$ concentrations in 
Table 1. Results of logistic regression analysis relating herd size (number of lactating cows) with producers' tendency toward adopting certain services or willingness to participate in some activities. Data are based on 612 survey responses from commercial dairies in the Northeast and Mid-Atlantic regions of the United States.

\begin{tabular}{|c|c|c|c|c|c|c|}
\hline \multirow[b]{2}{*}{ Services/activities } & \multicolumn{5}{|c|}{ No. of lactating cows } & \multirow{2}{*}{$\begin{array}{l}\text { Wald } \chi^{2} \\
\left(P>\chi^{2}\right)\end{array}$} \\
\hline & 50 & 100 & 200 & 500 & 1000 & \\
\hline & \multicolumn{6}{|c|}{ Probability of answering in the affirmative } \\
\hline DHIA membership & 0.60 & 0.65 & 0.73 & 0.89 & 0.98 & 0.0052 \\
\hline Professional AI service & 0.52 & 0.48 & 0.42 & 0.25 & 0.08 & 0.0158 \\
\hline Professional pregnancy check & 0.85 & 0.88 & 0.92 & 0.98 & 1.00 & 0.0548 \\
\hline Professional ration formulation & 0.81 & 0.90 & 0.97 & 1.00 & 1.00 & $<0.0001$ \\
\hline Regular forage testing & 0.71 & 0.88 & 0.99 & 1.00 & 1.00 & $<0.0001$ \\
\hline Awareness of $\mathrm{P}$ issues & 0.89 & 0.96 & 0.99 & 1.00 & 1.00 & $<0.0001$ \\
\hline Interest in lowering diet $\mathrm{P}$ & 0.22 & 0.25 & 0.29 & 0.47 & 0.75 & $<0.0066$ \\
\hline Interest in follow-up study & 0.40 & 0.55 & 0.80 & 0.99 & 1.00 & $<0.0001$ \\
\hline
\end{tabular}

survey responses with those from the on-site feed sample collection and analyses. There were 11 farms from which such paired data were available (Figure 4). The differences were relatively small, with an average deviation of 5.6\% (absolute values). Apparently, dietary $\mathrm{P}$ levels reported by producers were relatively accurate as compared to the measured data.

Not surprisingly, higher dietary $\mathrm{P}$ concentrations were not associated with higher milk yields, as illustrated in Figure 5. For the survey farms, regression analysis even suggested a negative association between dietary $\mathrm{P}$ concentration and milk yield, with a decrease of $1.2 \mathrm{~kg} / \mathrm{d}$ of milk per cow for every increase of $0.5 \mathrm{~g}$ of $\mathrm{P} / \mathrm{kg}$ in diets $(P=0.017)$, although the coefficient of determination was small $\left(\mathrm{R}^{2}=0.057\right)$. For the selected farms, no significant correlation between dietary $\mathrm{P}$ and milk yield was detected $(P=0.73)$.

Dietary $\mathrm{P}$ concentrations recommended by NRC range from 3.20 to $3.80 \mathrm{~g} / \mathrm{kg} \mathrm{DM}$ for cows producing 25 to $55 \mathrm{~kg} / \mathrm{d}$ of milk. Average milk yield approximates 25 $\mathrm{kg} / \mathrm{d}$ per cow in the Northeast and Mid-Atlantic regions or $27 \mathrm{~kg} / \mathrm{d}$ per cow in the United States (NASS, 2003).

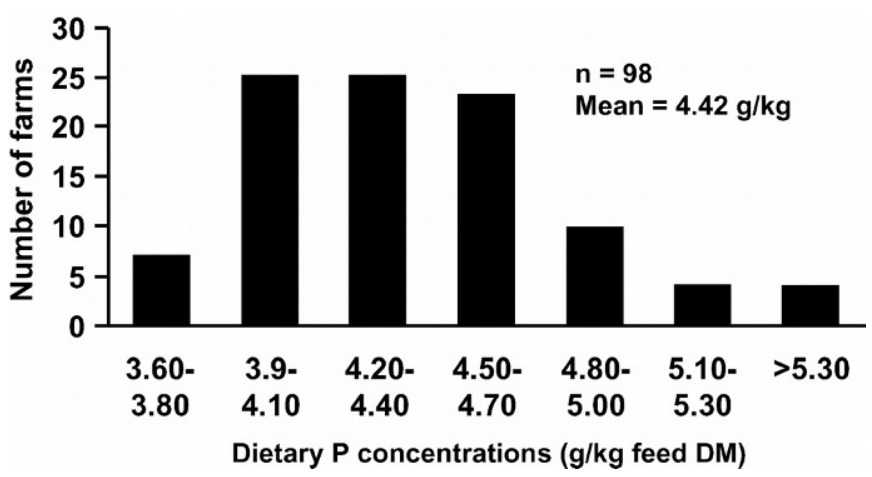

Figure 3. Dietary P concentrations for lactating cows reported in questionnaire survey conducted in the Northeast and Mid-Atlantic regions of the United States.
The NRC recommendations already include a modest safety margin (CAST, 2002). A number of research trials, as reviewed and summarized by Satter (2003), have proved that the NRC recommended range is adequate at the least. Data from the present work, derived from a large number of commercial herds over a broad area, provide field-based evidence to further support the adequate diet $\mathrm{P}$ range.

\section{Higher $\mathbf{P}$ in Diets Led to Higher $\mathbf{P}$ in Feces}

Higher dietary $\mathrm{P}$ led to higher $\mathrm{P}$ concentrations in feces; this is true for both acid digest total $\mathrm{P}$ and watersoluble $\mathrm{P}$ of fecal samples (Figure 6 ). The slope of the linear regression equations indicated that for each unit of dietary $\mathrm{P}$ increase ( $\mathrm{g}$ of $\mathrm{P} / \mathrm{kg}$ of feed $\mathrm{DM}$ ), there was

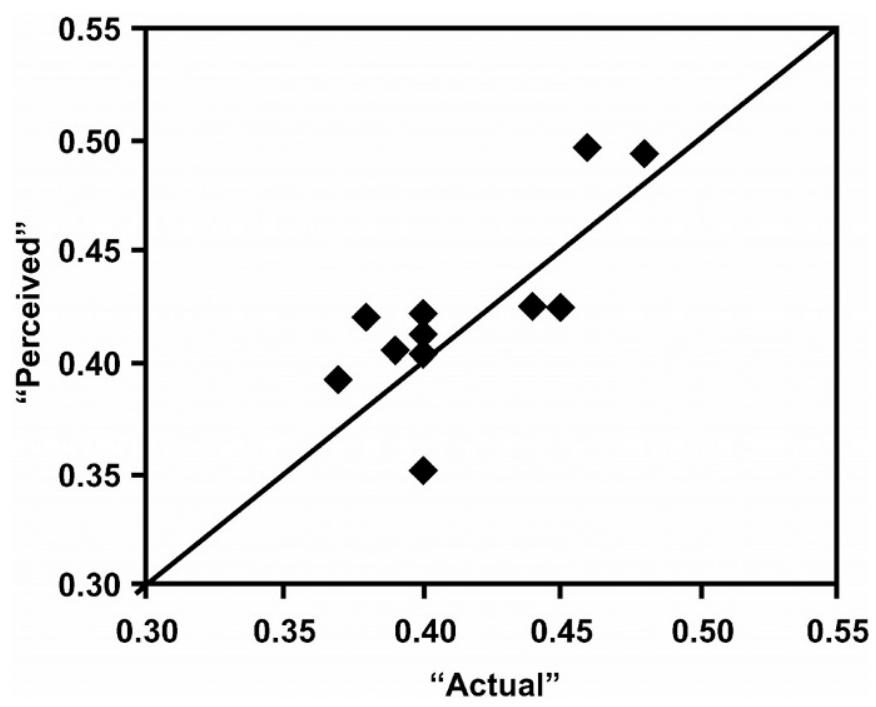

Figure 4. Dietary P concentrations "perceived" by producers as reported in questionnaire survey vs. "actual" as measured in feed samples collected for the same farms. Line represents a 1:1 relationship (i.e., perfect match). 


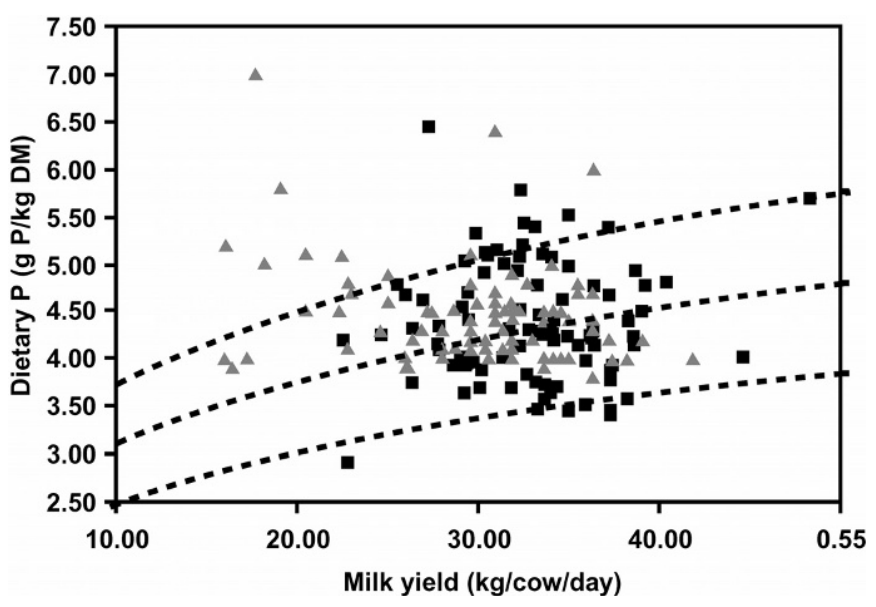

Figure 5. Dietary $P$ concentrations vs. milk yields as reported in a questionnaire survey (triangles) or obtained through on-site sample collection and analyses (squares). Higher dietary $\mathrm{P}$ is not associated with higher milk yield. The bottom curve represents recommended dietary $\mathrm{P}$ levels for varying milk yield according to NRC, and the upper curves are 1.25 and 1.50 times NRC.

an increase in feces of nearly $1.89 \mathrm{~g}$ of total $\mathrm{P} / \mathrm{kg}$ of fecal $\mathrm{DM}$, including $1.00 \mathrm{~g}$ of water-soluble $\mathrm{P} / \mathrm{kg}$ of fecal DM.

This kind of relationship was expected because all the diets in the current study had $\mathrm{P}$ concentrations close to or above the adequate $\mathrm{P}$ range recommended by NRC, and fecal excretion is the logical pathway for the excess $\mathrm{P}$ in diets. It has been demonstrated previously with data from feeding trials that nearly all of the excess $\mathrm{P}$ intake above the adequate $\mathrm{P}$ level was excreted in feces (Dou et al., 2002). Regarding the water

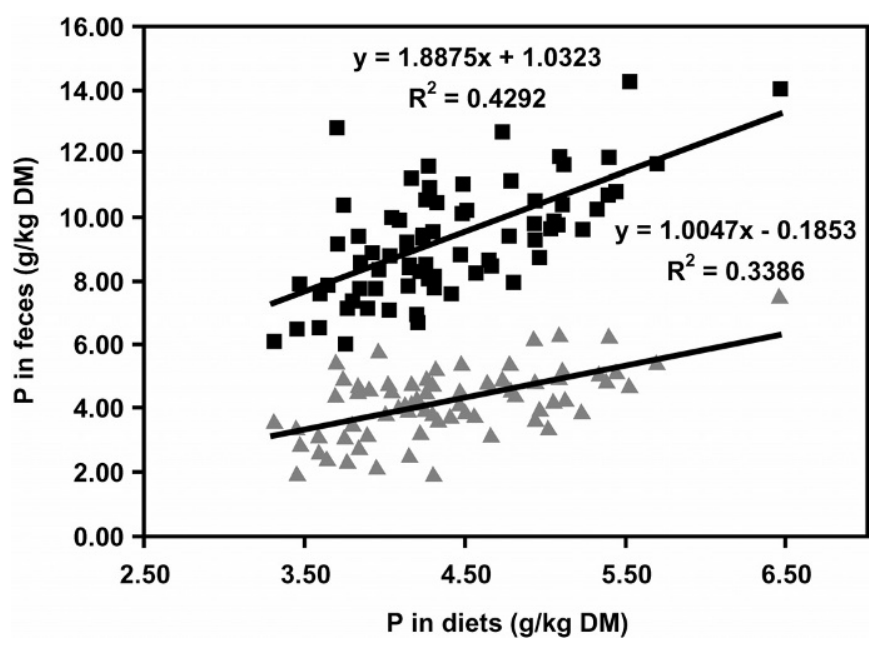

Figure 6. The relationship between $P$ concentrations in feces of lactating cows (squares for acid digest total $\mathrm{P}$ and triangles for water soluble total P) and in corresponding diets. Samples of feces and diets were collected from commercial dairies in the Northeast and MidAtlantic regions of the United States. soluble $\mathrm{P}$ in feces, there was an apparent discrepancy between results of the previous and current study. In the previous study, the extra $\mathrm{P}$ excreted in feces was almost entirely in the water-soluble fraction (Dou et al., 2002), but in the current study, only $1.00 \mathrm{~g}$ out of $1.89 \mathrm{~g}$ of total $\mathrm{P} / \mathrm{kg}$ of fecal DM was water soluble. This apparent discrepancy was due, at least partially, to differences in laboratory procedures. The previous study used dried fecal samples and the water-soluble $\mathrm{P}$ fraction was the cumulative $\mathrm{P}$ obtained through repeated, exhaustive water extractions, whereas the present study used wet-based fecal samples with a single extraction. This change was made in order to simplify sample handling and processing and to preserve the physical and chemical properties of samples as much as possible. The alteration was also made with an attempt to develop a quick method for evaluating the "fecal P indicator" concept proposed earlier for assessing dietary P status (Dou et al., 2002).

There is an important environmental implication associated with the fact that water-soluble $\mathrm{P}$ accounts for a substantial portion of total $\mathrm{P}$ increase in feces at higher dietary $\mathrm{P}$. Water-soluble $\mathrm{P}$ in manure represents the most vulnerable fraction concerning potential runoff loss once the manure is field applied (Dou et al., 2000; Sharpley and Moyer, 2000). Lowering dietary P concentrations may decrease P loss potential by several-fold, as measured in an agronomic plots setting (Satter, 2003). It is also noteworthy that even if dietary $\mathrm{P}$ is near the adequate level $(4.00 \mathrm{~g} / \mathrm{kg}$ of feed DM or less), water-soluble $\mathrm{P}$ still constitutes a significant part of total $\mathrm{P}$ in feces (detailed data not presented). This is consistent with findings in the previous study using samples from research feeding trials (Dou et al., 2002). Clearly, $\mathrm{P}$ contained in the organic feeds, either in the current study with diverse feed ingredients on many farms or in the previous study with the base diets carefully selected, was largely water soluble or readily digestible and thus highly available for cows.

\section{Relevant Issues}

Minimizing P supplementation is the key. Modern dairy diets typically contain 3.5 to $4.0 \mathrm{~g}$ of $\mathrm{P} / \mathrm{kg}$ of DM before mineral $\mathrm{P}$ is added (CAST, 2002). That is, diets using regular feedstuff without mineral $P$ contain adequate or slightly more than adequate amounts of $\mathrm{P}$ to meet cow needs. High-P diets $(4.5 \mathrm{~g} / \mathrm{kg}$ of $\mathrm{DM}$ or above) are almost always made so by using mineral $\mathrm{P}$ supplements. In our survey, when asked if mineral $\mathrm{P}$ was used in lactating cow diets, $60 \%$ out of 596 respondents answered "yes," 14\% replied "no," and $26 \%$ said they were "not sure." The excess $\mathrm{P}$ in diets added through the use of $\mathrm{P}$ minerals was unnecessary, re- 


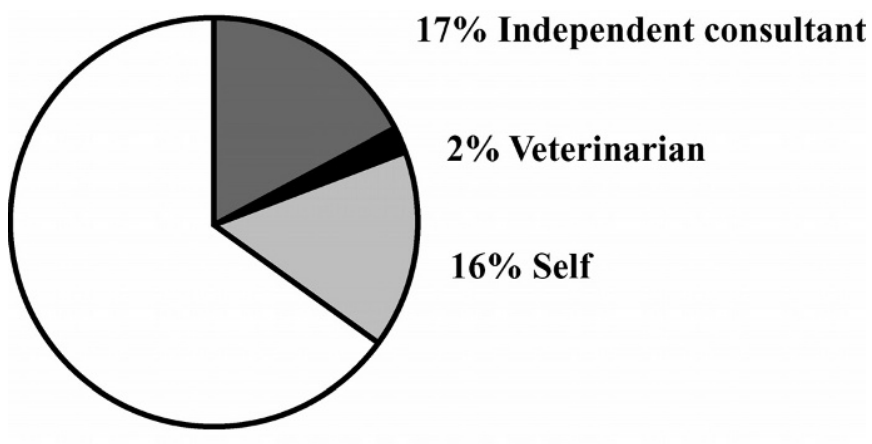

65\% Feed Co. personnel

Figure 7. Results from a dairy producer survey conducted in the Northeast and Mid-Atlantic regions of the United States, showing that ration formulations were made by professional service providers rather than producers themselves on most farms $(n=612)$.

sulting in higher feed costs and increasing the potential of $\mathrm{P}$ loss to the environment. Clearly, lowering or eliminating mineral $\mathrm{P}$ supplementation is the logical first step toward the reduction of excess dietary P.

Certain byproduct feeds are rich in P; for example, soybean meal contains $7.1 \mathrm{~g}$ of $\mathrm{P} / \mathrm{kg}$ of $\mathrm{DM}$; wheat middlings, $10.2 \mathrm{~g}$; and fishmeal, 30.1 (NRC, 2001). Thus, diets consisting of large amounts of P-rich byproducts may have $\mathrm{P}$ concentrations above $4.00 \mathrm{~g} / \mathrm{kg}$ of DM even without mineral $\mathrm{P}$ addition. Under this situation, reducing excess $\mathrm{P}$ in diets would involve a delicate balance between economic and environmental consequences because by-product feeds are often priced lower than other feeds. Using computer ration formulation software, it is possible to fine-tune the rations for minimal excess $\mathrm{P}$ while maintaining an acceptable feed cost. Of course, such ration fine-tuning would be a secondary measure compared to the importance and necessity of reducing or eliminating mineral $\mathrm{P}$ from diets.

Ration formulation is the critical control point. For most dairy operations, ration formulation is the first step in feeding management, which determines the type and amounts of diet ingredients, and thus, the concentration of $\mathrm{P}$ in the diet. Therefore, to lower excess dietary $\mathrm{P}$, ration formulation is the critical control point and those who perform the ration formulation are at the critical control position. From our survey, $84 \%$ of the herds had their rations formulated by professionals, whereas 16\% claimed to do their own (Figure 7). That is, the professionals rather than producers themselves are at the critical control position regarding the current presence of excessive $\mathrm{P}$ feeding and its future reduction.

Formulated rations set the dietary $\mathrm{P}$ concentrations on paper, which are then given to the producer to guide feed mixing and feeding practices. Naturally, there would be discrepancies between $\mathrm{P}$ formulated on paper

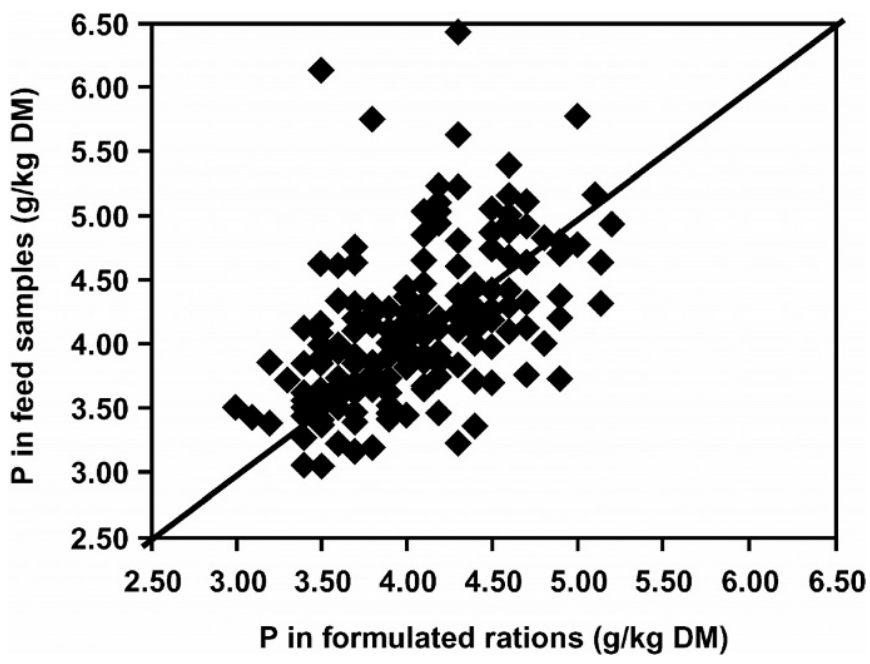

Figure 8. Phosphorus concentrations ( $\mathrm{g} / \mathrm{kg}$ of $\mathrm{DM})$ in actual diets fed to cows (samples collected from feed alleys) compared with $\mathrm{P}$ concentrations in formulated rations (on paper) for the same cow groups. Line represents a 1:1 relationship.

and $\mathrm{P}$ in actual feed delivered to the cows. To estimate the extent of discrepancy, 227 pairs of data ( $\mathrm{P}$ formulated on paper vs. P measured in feed samples) from selected farms were examined. Deviations (P measured in feed samples-P formulated in rations) were in both directions (Figure 8). Average deviation was $0.086 \mathrm{~g}$ of $\mathrm{P} / \mathrm{kg}$ of DM (absolute values). Sixty-seven percent of the measured data had a deviation less than $\pm 10 \%$ from the formulated values, and $16 \%$ of the data had a deviation greater than $\pm 15 \%$. Considering large variations for farm-origin data in general, it is fair to say that the majority of farms accurately implemented the formulated rations, in terms of $\mathrm{P}$ concentrations. Clearly, producers were feeding more $\mathrm{P}$ than cow requirements because they were guided by the rations formulated for them.

There were additional indications from the survey that producers relied on professionals for $\mathrm{P}$ feeding management. A total of 293 producers indicated that their nutritionists were taking care of the dietary $\mathrm{P}$ issue. Of the 222 producers who reported a lack of interest in lowering dietary $\mathrm{P}$, the most cited reason was "current level is recommended by nutritionist/vet" (64\%) (Table 2). There were also written comments in the survey from a number of producers indicating that they needed to discuss the P feeding issue with their nutritionists or veterinarians.

In fact, producers responding to the survey exhibited a fair understanding of the environmental issues related to $\mathrm{P}$ and appeared to be receptive to the $\mathrm{P}$ feeding management concept. Of the 612 valid returns, $89 \%$ indicated that they were aware of nutrient manage- 
Table 2. Producer responses when asked if they were interested in lowering dietary $\mathrm{P}$ of lactating herds in a questionnaire survey conducted on commercial dairies in the Northeast and Mid-Atlantic regions of the United States.

\begin{tabular}{ll}
\hline Item & $\begin{array}{l}\text { No. of } \\
\text { responses }\end{array}$ \\
\hline $\begin{array}{l}\text { Interested } \\
\text { Interested under these conditions }\end{array}$ & 126 \\
Evidence of no harm & 384 \\
Feed cost reduced & 288 \\
Reliable test available & 266 \\
Environmental loss decreased & 224 \\
Other dairymen lowered P & 150 \\
Not interested & 222 \\
Concerns cited & \\
Current level recommended & 147 \\
P helps with reproduction & 81 \\
Fear of production loss & 57 \\
Safety margin needed & 37 \\
Cows may need more P & 34 \\
Have always fed this level & 26 \\
\hline
\end{tabular}

ment regulations for animal farming, 47\% agreed there was a $\mathrm{P}$ surplus problem on animal farms, and $21 \%$ claimed that they had already reduced dietary $\mathrm{P}$ for lactating cows. When asked if they were interested in lowering dietary P, 126 said "yes," whereas the vast majority expressed their interest with certain conditions cited (Table 2 ). Also, there was a generally positive attitude toward the need for managing $\mathrm{P}$ for both good animal performance and environmental stewardship, reflected in more than 80 written comments. Many of the comments sought additional information, whereas only a handful expressed grudges toward regulatory measures or blamed others for polluting the environment. It is possible that producers who responded to the survey were progressive and educated and their attitudes toward the issues were positive in general. Nevertheless, the written questionnaire assured confidentiality to all survey recipients and the responding farms were reflective of the overall operations in terms of herd size distribution (Figure 2).

Reproductive performance remains to be adequately addressed. Reproductive performance, in addition to milk yield, is another key factor affecting decisions and practices regarding $\mathrm{P}$ feeding on dairy farms. There are long-held beliefs, particularly in the veterinary community, that $\mathrm{P}$ deficiency plays an important role in reduced fertility (Morrow, 1969; Steevens et al., 1971; Gerloff, 1996) and that feeding high-P rations improves reproductive performance. Because reproductive performance is economically important, attempts to lower excess $\mathrm{P}$ in dairy diets are often met with resistance from concerned producers and professionals, such as veterinary practitioners, alike.

Recent experiments found no negative impacts on reproductive parameters when cows were fed diets con- taining 3.10 to $4.00 \mathrm{~g}$ of $\mathrm{P} / \mathrm{kg}$ of $\mathrm{DM}$ (Wu et al., 2001; Satter, 2003). However, individually, these experiments did not withstand rigorous statistical testing due to limited sample number or experiment duration. Indeed, it is difficult to assemble enough cows in research trials under controlled conditions to develop statistically sound data regarding cow reproductive performance (Wu and Satter, 2000). This type of study would require large numbers of cows for a long period of time at substantial expense.

Through the ongoing project, data are being collected from approximately 100 commercial dairies in the five states, totaling more than 25,000 lactating cows. The data and sample collections were planned for a total of 3 yr (2002 to 2004). Preliminary analyses based on the 1st yr of data indicated no significant differences in reproductive parameters (conception rate, heat detection rate, pregnancy rate, days to first breeding, and days open) between groups into which the farms were tentatively categorized (dietary $\mathrm{P} \leq 3.80,>3.80 \leq 4.50$, and $>4.50 \mathrm{~g} / \mathrm{kg}$ of feed $\mathrm{DM}$ ). Comprehensive analyses will be performed at the completion of the project to identify the dietary $\mathrm{P}$ range that is adequate for both milk production and reproductive performance, while at the same time minimizing $\mathrm{P}$ excretion in feces. It is anticipated that the results from this farm-based, longterm project would adequately address concerns over dietary $\mathrm{P}$ levels and satisfactory cow performance, and further promote a wide adoption of the diet modification strategy.

\section{CONCLUSIONS}

Much effort has been undertaken in recent years through a variety of research and education activities, as well as regulatory measures, to manage $\mathrm{P}$ on animal farms for reduced environmental losses. Yet, dairy farms in the five-state area studied still fed excess $\mathrm{P}$ to lactating cows, averaging $34 \%$ above recommended levels. Higher $\mathrm{P}$ in diets was not associated with higher milk yields; this was true for data either reported by producers in the survey or obtained through on-site sampling and analyses. Higher $\mathrm{P}$ in diets did lead to higher $\mathrm{P}$ excretion in feces. Much of the increased fecal $P$ excretion was water soluble, the most vulnerable form for potential runoff loss after manure application.

Phosphorus overfeeding on most farms was attributed to excessive $\mathrm{P}$ in formulated rations, provided mostly by nutrition service professionals rather than producers themselves. Clearly, to lower excess $\mathrm{P}$ in diets, ration formulation is the critical control point and minimizing the excessive use of $\mathrm{P}$ minerals is the logical first step. 
Balancing $\mathrm{P}$ and other nutrients in diets as a frontend nutrient management approach has the unique advantage of not only lowering $P$ surplus on farms and subsequently reducing potential environmental losses, but also of saving producers' money in feed costs and preserving $\mathrm{P}$ minerals as nonrenewable resources. The amount of $\mathrm{P}$ minerals conserved could amass tens of millions of kilograms of $\mathrm{P}$ per year. To take advantage of this opportunity, concerted efforts are needed by all stakeholders, including nutrition service providers, feed supply industries, veterinarians, and producers. Toward this end, more data to adequately address concerns over dietary P levels and satisfactory cow performance, especially reproductive efficiency, are deemed necessary. Policies and incentive programs to encourage the adoption of diet modification as a front-end approach are essential.

\section{ACKNOWLEDGMENTS}

This work was funded by USDA Initiative for Future Agriculture and Food Systems Grant No. 2001-5210311334. The authors are grateful to all producers who responded to the questionnaire survey and those who are participating in the ongoing project. Thanks go to the following individuals for their assistance in survey preparation, farm visits, sample collection, laboratory analysis, or data summary and analysis: R. Munson, S. Michelone, B. Vecchiarelli, J. Beach, P. YearsleyJones, I. Rudik, R. Joseph, L. Chapuis-Lardy, T. Edwards, J. McKinney, and C. Olsen.

\section{REFERENCES}

Allison, P. D. 1999. Logistic Regression Using the SAS System: Theory and Application. BBU Press and John Wiley Sons, New York, New York.

CAST. 2002. Animal diet modification to decrease the potential for nitrogen and phosphorus pollution. Rep. No. 21 Council for Agric. Sci. and Technol., Ames, IA.

Dou, Z., K. F. Knowlton, R. A. Kohn, L. D. Satter, Z. Wu, G. Zhang, J. D. Toth, and J. D. Ferguson. 2002. Phosphorus characteristics in dairy feces affected by diets. J. Environ. Qual. 31:2058-2065.

Dou, Z., J. D. Toth, D. T. Galligan, C. F. Ramberg, Jr., and J. D. Ferguson. 2000. Laboratory procedures for characterizing manure phosphorus. J. Environ. Qual. 29:508-514.

Edwards, T., and Z. Wu. 2003. They prove you can reduce phosphorus. Hoard's Dairyman 148:570.

Gerloff, B. J., and E. P. Swenson. 1996. Acute recumbency and marginal phosphorus deficiency in dairy cattle. J. Am. Vet. Med. Assoc. 208:716-719.
Kleinman, P. J. A., A. N. Sharpley, A. M. Wolf, D. B. Beegle, and P. A. Moore, Jr. 2002. Measuring water-extractable phosphorus in manure as an indicator of phosphorus in runoff. J. Environ. Qual. 66:2009-2015.

Knowlton, K. F., and J. H. Herbein. 2002. Phosphorus partitioning during early lactation in dairy cows fed diets varying in phosphorus content. J. Dairy Sci. 85:1227-1236.

Lemunyon, J. L., and R. G. Gilbert. 1993. Concept and need for a phosphorus assessment tool. J. Prod. Agric. 6:483-486.

Morrow, D. A. 1969. Phosphorus deficiency and infertility in dairy heifers. J. Am. Vet. Med. Assoc. 154:761-768.

Murphy, J., and J. P. Riley. 1962. A modified single solution method for the determination of phosphate in natural waters. Anal. Chem. Acta 27:31-36.

NASS. Cattle. Available: http://usda.mannlib.cornell.edu/reports/ nassr/livestock/pct-bb/. USDA Natl. Agric. Stat. Serv. Accessed Feb. 26, 2003.

NRC. 2001. Nutrient Requirements of Dairy Cattle. 7th rev. ed. Natl. Acad. Sci., Washington, D.C.

Powell, J. M., Z. Wu, and L. D. Satter. 2001. Dairy diet effects on phosphorus cycles of cropland. J. Soil Water Conserv. 56:22-26.

Sansinena, M., L. D. Bunting, S. R. Stokes, and E. R. Jordan. 1999. A survey of trends and rationales for $\mathrm{P}$ recommendations among Mid-South nutritionists. Pages 51-54 in Proc. Mid-South Ruminant Nutr. Conf., Dallas, TX.

Satter, L. D. 2003. Management of dietary phosphorus in dairy production systems. Available: http://dfrc.wisc.edu/powell/. Accessed March 20, 2003.

Satter, L. D., and Z. Wu. 1999. New strategies in ruminant nutrition: Getting ready for the next millennium. Pages 1-24 in Proc. Southwest Nutr. Manag. Conf., Univ. Arizona, Tucson.

Sharpley, A. N., and B. Moyer. 2000. Phosphorus forms in manure and compost and their release during simulated rainfall. J. Environ. Qual. 29:1462-1469.

Shaver, R., and W. T. Howard. 1995. Are we feeding too much phosphorus? Hoard's Dairyman. 140:280-281.

Sims, J. T. 2000. The role of soil testing in environmental risk assessment for phosphorus. Pages 57-81 in Agriculture and Phosphorus Management. A.N. Sharpley, ed. Lewis Publ., Boca Raton, FL.

Sink, S. E., K. F. Knowlton, and J. H. Herbein. 2000. Economic and environmental implications of overfeeding phosphorus on Virginia dairy farms. J. Dairy Sci. 83(Suppl.1):143.

Steevens, B. J., L. J. Bush, J. D. Stout, and E. I. Williams. 1971. Effects of varying amounts of calcium and phosphorus in rations for dairy cows. J. Dairy Sci. 54:655-661.

Theiler, A., H. H. Green, and P. J. DuToit. 1928. Studies in mineral metabolism. III. Breeding of cattle on phosphorus deficient pasture. J. Agric. Sci. 18:369.

Valk, H., and L. B. J. Sebek. 1999. Influence of prolonged feeding of limited amounts of phosphorus on DM intake, milk production, reproduction and body weight of dairy cows. J. Dairy Sci. 82:2157-2163.

Walter, P. J., S. Chalk, and H. M. Kingston. 1997. Overview of microwave-assisted sample preparation. Pages 55-222 in Microwave Enhanced Chemistry: Fundamentals, Sample Preparation and Applications. H. M. Kingston and S. J. Haswell, ed. Am. Chem. Soc., Washington, DC.

Wu, Z., and L. D. Satter. 2000. Milk production and reproductive performance of dairy cows fed two concentrations of phosphorus for two years. J. Dairy Sci. 83:1052-1063.

Wu, Z., L. D. Satter, A. J. Blohowiak, R. H. Stauffacher, and J. H. Wilson. 2003. Milk production, phosphorus excretion, and bone characteristics of dairy cows fed different amounts of phosphorus for two or three years. J. Dairy Sci. (accepted) 